\title{
Violência e ausência de psicólogos nas escolas
}

| ${ }^{1}$ Marília Etienne Arreguy |

Resumo: Procuramos refletir sobre a prioridade da práxis psicológica no espaço escolar regional, analisando suas nuances e identificando os impasses que dificultam o trabalho psicológico em escolas regulares. No intuito de responder à questão surgida no decurso de dez anos lecionando o tema, investigamos: qual seria a dimensão prática da disciplina "Psicologia da Educação"? Para tanto, foram também executadas as seguintes atividades em campo: observações diretas e entrevistas semiestruturadas com psicólogos, pedagogos e outros profissionais que atuam em escolas públicas e privadas das cidades de Niterói, Rio de Janeiro, São Gonçalo e Itaboraí. Em um ensaio teóricodescritivo, relatamos os principais problemas encontrados: a enorme carência de psicólogos atuando em escolas e alguns aspectos da violência nesse contexto. Constatação igualmente pregnante foi a de que o trabalho de psicólogos em escolas constitui um paradoxo: o pedido de atuação em favor da emergência da palavra versus as resistências por parte da própria instituição de ensino que, de modo subliminar, "encomenda" o silenciamento, a adaptação e a correção de condutas indesejáveis, solapando a singularidade.

> Palavras-chave: psicanálise e educação; violência nas escolas; violência simbólica; micropolíticas; políticas educacionais.

\footnotetext{
1 Professora-pesquisadora do Programa de Pós-Graduação stricto sensu em Educação, Universidade Federal Fluminense. Niterói, Brasil. Doutora em Saúde Coletiva pelo IMS-UERJ; doutora em Pesquisas em Psicanálise e Psicopatologia pela Universidade de Paris Diderot. Rio de Janeiro, Brasil. Endereço eletrônico: mariliaetienne@id.uff.br
} 


\section{Contexto geral da pesquisa de campo}

As indagações preliminares de pesquisa surgiram do fato de trabalharmos com a "formação de professores", tanto na Pedagogia quanto na licenciatura, com aquilo que se convencionou chamar de "Psicologia da Educação". Esse nome parece um pouco óbvio, mas traz em si a marca de sua dubiedade: a psicologia "serve" à educação ou dita regras do topo de seu saber "científico" (JAMES, 2010) aos atores das instituições de ensino? Em que psicologia escolar podemos nos fiar para transmitir uma formação crítica aos professores? Além de nos fundarmos no estudo de autores que trabalham na interface da psicanálise com a educação e em entrevistas informais feitas a psicólogos e professores lotados em Coordenadorias Regionais de Educação do município do Rio de Janeiro, baseamo-nos em mais de 70 entrevistas semiestruturadas executadas por graduandos da Universidade Federal Fluminense (UFF), sob orientação desta autora e do monitor da disciplina Psicologia da Educação, Rafael Soares Gonçalves. Essa disciplina é obrigatória para graduandos em Pedagogia e para todas as licenciaturas. Os alunos fizeram incursōes, em duplas, em instituições de ensino públicas e privadas da Grande Rio, entre 2010 e 2011. Foram visitadas 65 instituições nas cidades de Niterói, Itaboraí, São Gonçalo e Rio de Janeiro (em algumas instituições, foram replicadas as entrevistas). Os relatórios de campo foram apresentados e debatidos em sala de aula, para posteriormente serem tabulados e analisados.

Diante da certeza da importância de se transmitir os fundamentos psicológicos que podem vir a auxiliar educadores, fomos ao campo e enviamos os alunos às escolas. Sem a pretensão de esgotar a multiplicidade das doutrinas e ideologias que embasam a conduta de profissionais "psi", apresentaremos alguns dados, mantendo em mente que sempre há "um resto" intocado sobre o que seria o âmbito das práticas psicológicas em escolas. Os resultados trouxeram a constatação da escassez, da inadequação e das resistências diversas ligadas ao trabalho psicológico em escolas. Em uma das instituições onde nos propusemos a falar e escutar os professores, obtivemos, pessoalmente, a seguinte resposta: "os professores não querem ser ouvidos".

Das 65 escolas visitadas (algumas foram visitadas mais de uma vez), em apenas $15 \%$ delas havia psicólogos contratados especificamente para exercer a função que lhes concerne por competência legal. Havia psicólogos em apenas uma das escolas públicas visitadas, e o restante dos 15\% de psicólogos atuantes 
estavam lotados nas escolas particulares da amostra. Outro dado importante foi o alto índice de relatos sobre a existência de violência nas escolas: 68\% dos entrevistados disseram ter presenciado ou saber que existia violência onde atuavam. Os principais aspectos relatados foram: assaltos às escolas, agressões físicas e verbais entre alunos, violência familiar, ameaças a professores, bullying. Destacou-se no relato de muitos dos profissionais entrevistados a fala recorrente de que violência só surge na escola como um reflexo da sociedade.

As perguntas que fizemos aos profissionais entrevistados voltavam-se principalmente para a definição de qual seria, de fato, o trabalho executado por psicólogos escolares ou do que imaginavam que seria esse trabalho, tendo em vista que, em $85 \%$ da amostra aleatoriamente selecionada, não havia psicólogos para entrevistar. Os alunos foram, então, instruídos a buscar quem respondesse por essas "questôes mais psicológicas na escola", tendo sido entrevistados muitos coordenadores pedagógicos, diretores, e, inclusive, professores (alguns deles eram psicólogos deslocados para a função de ensino, por falta de professor).

No intuito de saber em que medida havia influência da abordagem psicanalítica nas escolas, perguntamos também quais seriam os principais autores que norteavam o trabalho de psicólogos. Cerca de 90\% dos profissionais não sabia dizer com exatidão qual orientação teórica possuíam, falando sempre vagamente de Piaget, Vigotski e, em menor escala, Freud. Em apenas uma escola, a psicóloga presente por conta de um projeto temporário de pesquisa de inclusão através de jogos eletrônicos afirmou nortear-se por inúmeros autores cognitivistas contemporâneos. Além disso, abordamos como se davam os diagnósticos e encaminhamentos, se havia uma tendência a se recorrer à "medicalização", como era vista a "novidade" do conceito de bullying, como os profissionais lidavam com a questão da violência nas escolas, etc.

\section{Reflexões éticas sobre o papel do psicanalista que pesquisa em escolas}

Muitos dos alunos-entrevistadores declararam, no entanto, grande dificuldade para "entrar" nas escolas, encontrar profissionais a quem entrevistar, gerando sério questionamento sobre qual o "papel do pesquisador" na escola. Em que medida nossas perguntas seriam percebidas como ameaças aos entrevistados, quando se trata de esclarecer o papel de psicólogos escolares? 
Ao discutir o aspecto político imbricado no trabalho dos "intelectuais", a psicanalista Sophie de Mijolla-Mellor (2012) retoma ideias de Paul Ricoeur, permitindo considerar que a atividade intelectual requer certa "intrepidez" do pesquisador, pelo ímpeto "explorador" que opera em campo, no sentido de produzir suas teorias. Refletindo sobre a contiguidade entre teoria e prática, a autora relaciona o conceito de "espaço transicional" de Winnicott (1975) ao plano "político", ponderando sobre as consequências políticas da teoria e seu impacto nas atitudes dos "homens de ação", cujas práticas interviriam diretamente na realidade, por vezes, retroalimentando o processo teórico, por outras, "fabricando ideologias" (MIJOLLA-MELLOR, 2012).

Pensando nas imbricações entre teoria e ação política, consideramos que a pesquisa se configurou como uma investidura de "pesquisa-intervenção", inspirada numa perspectiva transdisciplinar (COSTA, 2002; RODRIGUES et al., 1995) e criativa (SANTOS, 1988), que bebe da fonte foucaultiana, mas que também se baseia numa instrumentalização do olhar e da escuta através do manancial fornecido pela teoria psicanalítica. Bem se sabe o quanto Foucault criticou inúmeras formas de normalização da vida, incluindo as práticas "psi" e, portanto, não poupou a psicanálise. Entretanto, na fase mais tardia de sua obra, Foucault demonstrou afinidades com o saber psicanalítico, resgatando o aspecto transgressivo advindo dessas práticas. Não obstante, as diferenças entre Foucault e a psicanálise não são de todo incompatíveis, porém tampouco são objeto deste trabalho (vide BIRMAN, 2000). Em todo caso, nunca nos pensamos como "neutros" em campo e, na medida em nos aventuramos a entrar em escolas e indagar sobre as práticas de psicólogos educacionais, produzimos alguma alteração, desvelando aspectos políticos e buscando a emergência da palavra transformadora. A suposta mudança produzida após a ida às escolas talvez tenha sido maior em nós mesmos, mas certamente introduzimos uma centelha de "dúvida" naqueles com quem interagimos, sobretudo ao propor falar sobre violência e refletir sobre a necessidade de psicólogos em escolas.

Suscitar questôes ligadas à violência, no Brasil, mexe com toda uma hierarquia rígida, presente nas escolas ao menos desde o período militar, em que falar poderia implicar "corte de cabeças". A histórica condição de violência simbólica (BOURDIEU, 1990) é reconduzida na política de contratações temporárias de professores e educadores. A livre expressão do pensamento pode gerar represálias 
institucionais quando se leva em conta que boa parte do corpo docente presente em escolas públicas ainda não conta com a estabilidade prevista em concursos públicos. Soma-se o fato de os diretores de escolas públicas serem, em geral, pessoas "indicadas" ou "escolhidas" por prefeitos, secretários de Educação, coordenadores regionais, nem sempre havendo um processo democrático na escolha dos dirigentes. Nesse sentido, a entrada de pesquisadores em campo supõe inúmeras resistências, sobretudo quando se trata da área "psi”, a qual se consolidou historicamente, em parte, como uma abordagem disciplinar inquisitiva, ou seja, uma prática de "exame" (CANGUILHEM, 1956; FOUCAULT, 1974; 2002), que acaba por pressupor uma espécie de ascendência científica (injustificada) em relação aos professores. Esse fato já fora criticado desde o final do século XIX por William James (2010). A presença de psicólogos também carrega todo um imaginário relativo à ideia de que "conseguem ver através dos pensamentos" das pessoas, pois lidam com a loucura, gerando ainda mais resistências.

No sentido de acentuar o aspecto intrusivo do pesquisador em campo, remetemos a Lacan (1964, p. 15), quando versa sobre o ato de pesquisar em psicanálise:

Gostaria, imediatamente, de evitar um mal-entendido. Vão me dizer - de qualquer modo, a psicanálise é uma pesquisa. Muito bem, permitam-me enunciar, e mesmo me dirigindo aos poderes públicos para quem este termo pesquisa, há algum tempo, parece servir de senha (..) para muitas coisas - o termo pesquisa, eu desconfio dele. Para mim, jamais me considerei um pesquisador. [...] Há aliás, no campo da pesquisa dita científica, dois domínios que podemos perfeitamente reconhecer: aquele em que se procura, e aquele em que se acha. [...] Se a pesquisa, nesta ocasião, nos interessa é pelo que, deste debate, se estabelece no nível do que se chama em nossos dias ciências humanas. Com efeito, vê-se aí como surgir, sob os voos de quem quer que ache, o que chamarei de reivindicação hermenêutica, que é justamente a que procura - que procura a significação sempre nova e jamais esgotada, mas ameaçada de ter suas asinhas cortadas por aquele que acha [...] (grifo da autora).

As palavras de Lacan (1964) são oportunas, pois os fatos que encontramos já se encontravam no horizonte de suposições que gostaríamos de interpretar. O "achado" dos dados quantitativos, cuja notoriedade científica foi rapidamente apropriada pela mídia e por instâncias do poder público, ${ }^{1}$ evidencia o que sempre esteve abaixo do nariz de qualquer cidadão esclarecido, mas que permanece num nível de invisibilidade cuja "violência simbólica" é força motriz (BOURDIEU, 1990; ARREGUY et al., 2012). É na produção de nossas atividades em campo, refletidas neste texto, que buscamos extrair novos rumos para o "achado", de modo 
a fazer face ao congelamento da "farsa", bem descrita por Žižek (2011), como o modo indiferente, velado, com que lidamos com nossas mazelas educacionais, ou seja, criando uma série de dispositivos que não alteram de fato as condições exploratórias do capitalismo global (FORRESTER, 1997; ŽIŽEK, 2008).

Voltando à citação de Lacan (1964), é na mídia e na política que temos nossas "asinhas cortadas", pela forma em que se tenta manipular o que aqui procuramos interpretar. Portanto, é necessário dar sentido, norteados por uma ética da sutileza e do cuidado, aos "achados" em campo. Com inspiração em Richard Rorty (1979), entendemos que os dados qualitativos que interpretamos, assim como as precárias estatísticas que deles estabelecemos, não são um "espelho da realidade", assim como a "filosofia não é um espelho platônico da essência da natureza", nem a ciência é um sinônimo da Verdade. De todo modo, ao encararmos esta pesquisa, fazemos, de fato, um exercício "do político" (MIJOLLA-MELLOR, 2012) pela via da pequisa.

É interessante refletir sobre o papel político do pesquisador, principalmente no que se refere a que pesquisa e de que tipo intervenção psicológica se trata quando "investigamos" as escolas que visitamos. Até que ponto pesquisa-se para produzir mudanças na realidade? Em que medida muitas pesquisas estão voltadas a interesses mercadológicos ou, então, possuem interesses políticos? Até que ponto manter os psicólogos fora das escolas atende a interesses corporativistas? Sem ousar responder a essas indagaçôes, voltemos aos nossos "achados" em campo.

\section{Algumas constatações oriundas das conversas nas escolas}

A ausência de psicólogos na maioria das escolas públicas não é um fato isolado. Possui uma história, cuja condição micropolítica assinala embates e dissidências, apontando a disputa de poder e certo corporativismo no campo das práticas educacionais, sobretudo quando se trata da difícil relação entre pedagogos e psicólogos (LAJONQUIÈRE, 2010).

Conforme afirmam as pesquisadoras Marisa Rocha e Kátia Aguiar (2010, p. 72): “[...] os psicólogos, a tempos personae non gratae nas escolas municipais da rede do Rio de Janeiro, voltam a ser convocados (re)acionando a velha aliança entre psicologia e educação". Tal afirmação, cujo histórico merece ainda mais investigaçōes, nos faz pensar nas fragilidades da atuação de psicólogos em escolas. Até que ponto seria adequado manter psicólogos exclusivamente no campo da 
saúde, como sustentam algumas correntes psicológicas? É evidente que não se

pode confundir espaços de atuação, pois fazer psicoterapia em escolas seria uma aberração do ponto de vista ético. Contudo, não seria justo apostar na mediação de conflitos escolares a ser feita por psicólogos ao invés de "psicologizar" e/ou "medicalizar" lançando todo e qualquer aluno dito problemático na vala comum da indicação terapêutica? Mais grave ainda, na ausência de uma escuta dedicada às vicissitudes da escola, é quando a solução à mão passa a ser "judicializar" (CRPSP, 2010), enviando alunos agressivos direto para o Conselho Tutelar ou mesmo para os tribunais. Essa conduta punitiva é potencializada na ausência de profissionais capacitados que poderiam intervir com a palavra e dar atenção à singularidade, oferecendo o necessário continente da simples presença implicada com o sofrimento de alunos e professores.

Em nossa pesquisa de campo, houve muitas respostas bizarras. Alguns profissionais, mesmo secretários e porteiros, chegaram a "rir na cara" (sic) de nossos aprendizes de entrevistadores, ao lhes dizerem que não havia sequer um contingente de professores suficiente para atender às turmas, quanto mais psicólogos atuando em escolas públicas regulares. Ouvimos também repetidas afirmativas de que não havia psicólogos na rede pública, que não isso simplesmente não existia, que se tratava de uma ficção. Quando raramente era encontrada alguma pessoa com formação em psicologia nas escolas visitadas, em geral ela não exercia essa atividade, seja por se tratar de um(a) professor(a) com formação adicional em psicologia, ou ao contrário, de um psicólogo(a) desviado de função por falta de professores na rede. Quanto à rede privada, visitada em menor escala (17\% da amostra), em geral havia psicólogos, mas em número reduzido, em horários restritos, atendendo a uma quantidade desproporcional de alunos - por exemplo, um psicólogo para mil alunos.

Quando os educadores reconheciam a necessidade do apoio de psicólogos, dentro ou fora das escolas, abria-se um rosário de dificuldades: 1) a baixa eficácia dos encaminhamentos terapêuticos por $n$ motivos (filas nos setores públicos de saúde, dificuldade de ter que passar sempre antes pelo médico, que muitas vezes "medica" sem reencaminhar o/a aluno/a ao psicólogo, e sem tampouco dar um retorno ao professor); 2) insuficiência financeira, e mesmo prática, dos pais para levar seus filhos à psicoterapia; 3) existência, quando muito, de projetos psicológicos temporários impondo aos profissionais da educação um conjunto 
de regras normativas sobre o funcionamento do cérebro, como diagnosticar e tratar TDAH, TOC, TAG, BULLIES, TOD ${ }^{2}$ etc., e formatando o trabalho "psi" numa lógica tecnicista, cientificista, reducionista e estigmatizante. Essa lógica se imiscui ao longo da modernidade no terreno vivo das aprendizagens, engendrando ideologias respaldadas pelo aval científico (FOUCAULT, 2000; ARREGUY; GONTRAN, 2012). Seria possível fazer algo diferente?

Muitas das pessoas que conversaram com os nossos "alunos-pesquisadores" afirmaram que "faziam o trabalho de psicólogos", ou ainda, que atuavam "como se fossem psicólogos”, já que, em geral, não havia nenhum psicólogo atuando na referida escola. $\mathrm{Na}$ ausência de psicólogos, os educadores entrevistados (na maioria mulheres) diziam ter que improvisar, "aconselhando" alunos, sobretudo chamando os pais para conversas no sentido de orientar e disciplinar seus filhos. Foi também recorrente a fala de que a falta de psicólogos nas escolas dificultava muito o trabalho, pois a grande maioria dos profissionais entrevistados, cerca de $75 \%$, reconheceu que seria desejável a presença desses profissionais atuando em auxílio à educação.

Outro aspecto chamou nossa atenção: a maioria dos entrevistados afirmou que a maior dificuldade para resolver os casos de alunos com conflitos específicos, seja de aprendizagem, seja de comportamento, era o relacionamento com os pais. Em pelo 21 das 30 entrevistas feitas no primeiro semestre de 2011, ou seja 71\% dessas entrevistas, houve uma tonalidade de culpabilização das famílias, acusadas de não se interessarem pelos destinos de seus filhos nas escolas. Encontramos forte associação entre dificuldades escolares dos alunos e a afirmação da existência de negligência nas famílias. Soma-se que, em $43 \%$ do total das entrevistas, houve a tendência a se atribuir a causa da violência apresentada pelos alunos a suas respectivas famílias.

Foi também relatado que havia muitas limitaçôes por parte dos pais para compreender os problemas apresentados por seus filhos e, mais ainda, para aderirem a quaisquer demandas de levar suas crianças para um atendimento psicológico especializado fora da escola, sobretudo nas escolas cujo público é de baixa renda. Ora, há ainda muito preconceito em relação ao trabalho do psicólogo clínico, cuja demanda de atendimento parece colada ao estigma da loucura. Além disso, foi muito comum a rotulação de alunos sob a rubrica de supostas doenças neurológicas, tendência que podemos atribuir às áreas positivistas da psicologia e à própria 
gana neurocientífica em criar uma série descrições nosológicas, já denunciadas como falhas e pseudocientíficas (TSUJI; MOYSÉS; BATISTA, 2011; CRPSP, 2010). Por outro lado, soa como uma espécie de alívio a contraditória satisfação com que pais e estudantes alardeiam diagnósticos psicopatológicos recebidos rapidamente por psiquiatras e psicólogos comportamentais, na medida em que isso os desculpabiliza pela "doença”. A causa de todo mal-estar é atribuída ao cérebro, o que acaba por desresponsabilizar as famílias. Em outro viés, a atividade de psicólogos orientados pela psicanálise preconiza que o diagnóstico não deve ser proclamado ao paciente, reservando o domínio do enigma para a implicação do sujeito em sua tomada de responsabilidade por seus atos (AULAGNIER, 1979).

Considerando as condições encaminhamento, quando as barreiras do preconceito em relação ao trabalho psicológico são vencidas e alunos com dificuldades expressivas são encaminhados para atendimento psicológico fora da escola, outros impedimentos ainda mais severos se apresentam, como a escassez de serviços públicos suficientes para atender à demanda de psicoterapia das crianças e dos adolescentes oriundos das escolas públicas. São mais que evidentes as distorções entre o acesso público e privado ao atendimento psicológico clínico.

As crianças e jovens que conseguem buscar um atendimento psicoterapêutico na rede pública do Estado do Rio de Janeiro, muitas vezes, ficam nas filas de espera de postos de saúde, CAPS (Centro de Atendimento Psicossocial), ou Serviços de Psicologia Aplicada das faculdades, já superlotados, quando de fato oferecem esse serviço. Nos setores em que estagiários, graduandos de psicologia, são os responsáveis pelo atendimento (embora possam ter supervisão clínica de qualidade), é corriqueiro o fato de não haver continuidade no trabalho, uma vez que esses profissionais em formação têm férias longas, se formam e nem sempre conseguem manter o vínculo com seus pacientes, o que é fundamental no cuidado a médio e longo prazo.

Uma das poucas psicólogas que encontramos atuando numa escola pública, cuja orientação de trabalho era psicanalítica, fez uma associação distinta da maioria dos entrevistados. Ao invés de atribuir às famílias a origem dos conflitos escolares, apontava a implicação da escola e, mais, do sistema institucional educacional no fracasso e inadequação escolar. Maria Helena de Souza Patto (1990) já acentuara as questões políticas e socioeconômicas no cerne da falácia do ensino público brasileiro, ao mostrar que o "fracasso escolar" se associa a uma 
complexidade de aspectos, desmistificando a culpabilidade atribuída pela escola, em grande parte, às famílias ou, especificamente, ao aluno. Aí vemos novamente o problema da prioridade: como atentar para questóes psíquicas se faltam professores, quanto mais psicólogos e assistentes para um trabalho mais próximo às famílias e comunidades? $\mathrm{O}$ fosso aumenta quando vemos a disparidade entre a qualidade do ensino privado (que, em geral, conta com presença de psicólogos e boa infraestrutura) e o terreno inóspito de muitas escolas públicas, cuja escassez de psicólogos é apenas a ponta de inúmeras carências. A prioridade, tanto na esfera pública quanto na privada, parecem ser os investimentos em tecnologias de ensino, como a compra de computadores e informatização do espaço escolar, aspectos importantes, que no entanto não têm necessariamente a contrapartida no investimento em humanidades.

A realidade é que, ao contrário do que se poderia esperar no âmbito das competências de psicólogos escolares, muitos professores são obrigados a tentar resolver os conflitos de alunos sem ter apoio algum, sem ter suporte sequer para eles mesmos, conforme relataram. Ora, para se efetivar de um modo realista a tão almejada educação para todos e a inclusão social, é preciso uma composição complexa de profissionais, buscando constantemente o aprofundamento de seus conhecimentos e de suas práticas em escolas. Além de psicólogos (e assistentes sociais) efetivos nas escolas, os próprios professores não podem ser totalmente subordinados aos interesses do lucro ou a micropolíticas de silêncio e favorecimento.

Nesse sentido, podemos dizer que a violência no ensino, seja entre as crianças e jovens, seja envolvendo professores e famílias, está ligada ao fato de que todos sofrem uma "violência objetiva", específica do sistema capitalista exploratório globalizado (ŽIŽEK, 2008). Mais ainda, sofre-se de um sistema produtivista que assemelha professores aos ratos de laboratório comportamental, como se tivessem que ficar apertando a barra reforçadora da caixa de Skinner, ao trabalharem sem parar, para ganhar "prêmios" (SUWWAN, 2011). Assim, professores e alunos são apenas uma "cifra" (DELEUZE, 1990), ao invés de serem valorizados e reconhecidos.

Em uma das entrevistas de campo, um professor afirmou categoricamente fornecer diagnósticos aos pais, como, por exemplo, "seu filho é hiperativo", subsequentemente sugerindo o encaminhamento da criança ao médico. Por mais tato, sensibilidade e conhecimento de causa que tenha esse professor, evidentemente, não é sua função definir os transtornos clínicos das crianças. 
Supomos que essa prática seja mais comum do que se pôde admitir pelos entrevistados. Afinal, o inconsciente opera por revezes: o que é manifesto sempre esconde algo latente, ora de modo absolutamente contrário, ora de modo oblíquo a uma percepção corriqueira.

A crítica que fazemos às aventuras diagnósticas de professores, pedagogos, pais e até mesmo psicólogos de orientação cognitivo-comportamental apoiados nos avanços tecnocientíficos aclamados pela mídia não é por causa de um corporativismo fora de moda. É por conta da especificidade de um trabalho que, mesmo em se tratando de profissionais já formados e especializados em universidades reconhecidas, possui sutilezas para as quais não basta apenas alguém muito bem preparado, mas sim alguém competente por Lei, que possa conviver no chão da escola, imbuído de sua práxis, para estar apto a atuar.

Quando questionados sobre o tema da violência, boa parte das respostas dos profissionais mostraram consciência sobre a amplitude do problema: trata-se de um problema sistêmico, um problema da sociedade. Os referidos casos de bullying não chegavam a preocupar tanto assim os responsáveis pela coordenação das instituições visitadas, porém essa designação parece estar na moda. De fato, certo utilitarismo da expressão "bullying" escamoteia a complexidade do problema da violência, desviando prioridades. Alguns dos educadores entrevistados tentavam defender a integridade da imagem de suas instituições ao dizerem, por exemplo: aqui não tem violência, só umas três vezes por ano vem o camburão! Outras afirmativas contraditórias mostravam que a escola era segura, pois havia câmeras por toda parte e sempre tinha ronda policial dentro do pátio, evidenciando o caráter de controle por coerção punitiva inserido na estrutura educacional.

Com um cenário diferenciado, o município do Rio de Janeiro apresenta um contingente de psicólogos concursados para o Sistema Único de Saúde (SUS) que foram empossados para atuar nas Coordenadorias Regionais de Educação. Em entrevista feita a uma psicanalista que atua nesse setor, foram desfiladas dificuldades enormes, desde o princípio de sua inserção em campo. Em primeiro lugar, relatou que os profissionais empossados se ressentiam pelo fato de serem especialistas clínicos e não escolares. Em segundo lugar, quando chegavam às escolas, eram forçados a implementar projetos prontos, de modo que não podiam participar do processo criativo, nem tampouco podiam exercitar seu olhar clínico (ainda que em contexto institucional), voltando-o para a escuta das singularidades. 
Os psicólogos (em maioria de orientação psicanalítica, dadas as características bibliográficas do último concurso para psicólogos do SUS, ocorrido no município do Rio de Janeiro em 2005), chegaram a ser estimulados a "vigiar" os professores para ver se realmente estavam aplicando o conteúdo obrigatório dos projetos da Secretaria de Educação, através do preenchimento de formulários objetivos.

O que poderia ser um ganho, com a inserção de psicólogos ou de projetos na rede educacional, acaba sendo um processo permeado por grandes equívocos, na medida em que, mais uma vez, psicólogos e professores são colocados em disputa e vigilância mútua, sendo também cooptados a induzirem à medicalização.

Outra fala marcante, pronunciada em um dos eventos organizado pela Escola Brasileira de Psicanálise em 2012, um médico pediatra disse ser comum a prática de psiquiatras solicitarem que professores preencham formulários objetivos, de acordo com critérios de laboratórios farmacêuticos. Os professores são treinados a selecionar itens puramente objetivos que são utilizados para respaldar tecnicamente a opção pela medicação. Esse médico afirmou discordar dessa prática, por sua vez, solicitando aos professores a escrita de relatórios descritivos em que pudesse observar e narrar quais suas impressões subjetivas sobre o aluno, ao invés de enquadrá-lo num conjunto de dados normativos preestabelecidos.

\section{Reflexões sobre o modo como se atua na escola}

A disjunção entre orientação teórica versus a posição efetivamente adotada por diferentes profissionais "psi" no campo educacional denuncia embates epistemológicos históricos, na medida em que os profissionais da educação, frequentemente cooptados por uma lógica hierarquizada e segmentada, por vezes atendem a interesses externos às prerrogativas éticas da profissão, aliando-se às demandas mercadológicas exteriores às necessidades da escola, e vinculando suas práticas aos interesses da indústria (informática, alimentícia, psicofarmacológica, de bens de consumo, cultural, etc.). Outra questão importante, que se situa no plano da micropolítica (FOUCAULT, 1974), é o aspecto contraditório da ausência versus presença de psicólogos em escolas. Ao mesmo tempo em que sua atuação é solicitada pelos educadores (professores, diretores, coordenadores, funcionários, famílias), na medida em que são reconhecidos como importantes propiciadores da formação e restauração de elos entre os pares, e, igualmente, por ajudarem a dissolver conflitos inerentes ao "mal-estar" na educação (FREUD, 
1996; KUPFER, 1983; 2000; ESTEVE, 1999; LAJONQUIÈRE, 2010),

também podem servir como meros asseguradores do dispositivo disciplinar.

A inserção de psicólogos nas escolas, então, além de solicitada, é temida, pois apresenta (consciente ou inconscientemente) a promessa de somar forças no estabelecimento da disciplina, com a expectativa de constituição de "corpos dóceis", conforme definiu Foucault (1974). O trabalho de psicólogos pode ainda ser associado ao imperativo de se fazer alunos (e inclusive professores) produzirem sem parar, como se fossem autômatos ultra-adaptáveis, que ao invés de apreender significados e atribuir novos sentidos, "empreenderiam" tarefas num ritmo "internético", em que a aprendizagem infantil seguiria a lógica das empresas (DELEUZE, 1990). Alunos devem corresponder a padrões de excelência ou devem ser instrumentalizados como objeto de suspeita. Por outro lado, representando uma dicotomia insolúvel, vemos o imperativo do gozo da juventude eterna determinando uma inversão na prática pedagógica. Segundo Dufour (2009), ao associar a lógica do gozo aos excessos dos jovens contemporâneos determinados pela "pornocracia" do marketing de consumo:

O que aí se manifesta é a inversão de sentido da relação pedagógica. Essa inversão indica que a geração anterior é liberada e mesmo expulsa do dever educativo de que se prevalecia. E se nela deve haver educação, será com a condição de inverter o seu sentido, pois se trata de uma educação para gozar. (p. 35).

A inversão pedagógica de que se trata estaria fundada na inversão dos valores geracionais. Os imperativos de gozo passam a se impor dos jovens aos adultos. Assim, os objetivos disciplinares da educação encontram-se em crise, embora ainda sejam bastante presentes no cenário educacional. De um lado, a demanda de produção e controle naquilo que ainda prevalece do modelo disciplinar, sobretudo no ensino privado e em ilhas de excelência do ensino público. De outro, a inversão pedagógica em que crianças e jovens não veem mais seus pais e mestres como modelos ideais, sendo mais determinados pelo espetáculo midiático e pelas infinitas possibilidades da rede. A querela entre o ensino tradicional disciplinar e a ampla possibilidade das aprendizagens via internet surge como uma nova realidade a ser compreendida (vide SIBILIA, 2012).

Constituída pelo projeto de disseminação do medo (BATISTA, 2010) no bojo do higienismo (FOUCAULT, 2002), a disciplina imposta pela "sociedade de risco" (CARVALHO, 2005) é ainda vigente, porém se apresenta com novas roupagens, visando neutralizar todos aqueles que representam um "resto" em 

caso específico das escolas públicas, o alunado é objeto de constante controle, disseminado, por exemplo, no recrudescimento da vigilância com o uso de câmeras filmadoras por toda parte, pela instalação maciça de grades em todas as aberturas e, mais recentemente, com o dispositivo de introdução de policiais militares nas escolas públicas estaduais. ${ }^{3}$ Evidentemente, esse dispositivo não foi utilizado em escolas particulares. A tomada dessa medida salienta o quanto o valor da palavra vem cedendo em função do recrudescimento de uma sociedade competitiva, investigativa e intervencionista, usando o recurso à força como justificativa dissimulada para garantir uma condição pedagógica. Tal ação de segurança se impõe às camadas mais empobrecidas da sociedade fluminense ao invés de se implementar e aprimorar as atividades de profissionais de ciências humanas e saúde em escolas, sobretudo, valorizando a atuação conjunta de professores, psicólogos e assistentes sociais. ${ }^{4}$ Essa seria uma forma de reforçar o nível primário de atenção à saúde em escolas através da interação de diferentes saberes.

A manutenção da divisão social - explícita na segmentação entre ensino público e privado - permanece como uma premissa da "sociedade de controle" (DELEUZE, 1990) ligada, por sua vez, de modo sutil, à ideia de "formação permanente". A estratégia de manter professores e alunos constantemente ocupados com a formação e a produção permanentes esgota a energia crítica e a força política dos sujeitos. A exigência de trabalho permanente foi anunciada por Deleuze (1990) como uma característica do "controle" virtualizado, na medida em que a função de produção (que engloba trabalho, estudo, culto à saúde e ao corpo, etc.) passa a dominar permanentemente a vida dos sujeitos com exigências cada vez mais intensas. Assim, o controle de todas as esferas da vida, inclusive a virtual, representaria uma hipersofisticação do modelo panóptico (FOUCAULT, 2000), na medida em que as formas mais intensas de controle passam a ser virtuais, ou seja, baseadas num modelo informático invasivo (ASSANGE et al., 2013).

Nesse contexto, os saberes produzidos nas escolas, por professores, psicólogos, alunos e demais técnicos, perde seu valor diante da imposição de projetos hegemônicos totalitários (ARREGUY, 2012), que ignoram a singularidade de cada instituição de ensino, supondo um mesmo modelo "para todos". Se, por um lado, a justificativa de projetos únicos tem o mérito de buscar uma base comum para as aprendizagens, por outro pode se constituir como forma de alienação do ensino 
aos interesses de mercado, em oposição à valorização da criatividade e liberdade na construção de projetos voltados às realidades culturais locais. Podemos citar exemplos de projetos científicos veiculados, principalmente em escolas públicas; projetos de bonificação de professores por premiação; projetos de implementação de conteúdo educacional padronizado; projetos de empreendedorismo com parcerias público-privadas nas escolas; projetos de medicalização para detectar alunos hiperativos, agressivos, inadaptados, opositores, com déficit de atenção, autistas, etc. Muitas dessas iniciativas estão relacionadas ao crescente domínio de políticas neoliberais no campo educacional, ou seja, ao fortalecimento da lógica empresarial de massa a ser introduzida inclusive no ensino público.

Diante desse contexto, como se dá a práxis atual de psicólogos escolares? Em que medida sua atuação é orientada pela ética ou corrobora mecanismos ultramodernos de controle, típicos dos modelos comportamentalista, midiático, cibernético ou psicofarmacológico? Até que ponto os psicólogos escolares seriam livres para promover a expressão das singularidades, bem como para trabalhar com as diversidades presentes na escola? Quais práticas psicológicas seriam mais facilmente cooptadas pelo modelo neoliberal que visa o lucro e o controle na educação?

\section{A lógica mercantilista de adaptação do escolar}

Qualquer pessoa, por mais leiga que seja, é capaz de afirmar com toda a certeza que a principal "solução" para os problemas de uma comunidade, de uma cidade, de um país, encontra-se na Educação. Entretanto, vemos a incidência nefasta do aspecto político-econômico no que se refere ao aporte de verbas para o setor educacional, sobretudo devido à forma em que esses investimentos são efetivados. Há uma panaceia de slogans como: "todos pela educação", "globalização do ensino", "empreendedorismo no âmbito da pesquisa", "gestão educacional", marcando um campo cujos investimentos padronizados são recobrados sob a pena da alienação. Afora os "diagnósticos ultramodernos" (O GLOBO, 10/06/2013), que buscam esquadrinhar a vida emocional dos alunos a partir de testes quantitativos e intervenções medicamentosas abusivas (CRPSP, 2010). Essas abordagens investem em fórmulas lideradas por economistas que justificam atitudes aceleradas e pouco refletidas baseadas na contratação de projetos em larga escala que pouco ou 
nada transformam em relação à permanente divisão social refletida nas políticas educacionais bipartidas entre público e privado. Propostas ditas "inovadoras" são apresentadas de forma sedutora a todo momento através do "espetáculo" midiático (DEBORD, 1997), ao prometerem soluçōes quase mágicas para todas as agruras do processo de ensino e aprendizagem. Usualmente são alardeadas soluções imediatistas muitas vezes apoiadas na seara da avaliação e da psicopatologia, fornecendo diagnósticos que podem estigmatizar crianças e jovens durante toda uma vida. Criam-se grandes promessas em relação às expectativas dos pais e professores, porém, os resultados do uso cada vez mais vasto de medicamentos da alma são pouco palpáveis (ROUDINESCO, 1999), principalmente porque tendem a desresponsabilizar o sujeito diante de seu sofrimento, funcionando mais na esfera do entorpecimento para a adaptação. Muito pouco se vê investir numa emancipação política e crítica dos sujeitos em formação.

Nesse modelo, as prioridades são deliberadamente confundidas. A sutileza afetiva do processo de ensinar e engajar o pensamento crítico de crianças e jovens cede diante do quase exclusivo investimento na compra de computadores e na aplicação de métodos objetivos que buscam padronizar resultados (ARREGUY, 2011) e produzir estatísticas que diminuam o malfadado "risco Brasil". O sistema neoliberal aplicado ao ensino inverte o que deveria ser o investimento prioritário na troca intersubjetiva legítima e produtora de conhecimento, pelo anseio fetichista por "produtos" educacionais. Não interessa saber da vida e dos projetos dos alunos, mas apenas transformá-los em "quantidades" a serem exploradas pelo livre mercado. Justificando essa lógica, as estatísticas substituem facilmente a vitalidade das açôes. Exploram-se critérios objetivos de "qualidade e produtividade" que continuamente obliteram o inefável das relações humanas, ignorando dificuldades subjetivas e sociais, na medida em que se tenta ajustar as incontornáveis vicissitudes do aprender à medida rígida do rendimento. As atividades de psicólogos, nesse meio, acabam muitas vezes sendo puramente normativas, seja por estarem atreladas ao lucro da escola e de grandes corporações, seja por cederem ao jogo de interesses disciplinares.

Num contexto em que as marcas e insígnias de sucesso econômico valem mais do que as pessoas, em que a produção de mercadorias e a incrementação de técnicas, sob a roupagem de inovação tecnológica valem mais do que vidas, ou seja, quando a dimensão "tecnicista" é priorizada em detrimento de se investir 
especificamente em profissionais da educação, negando (ou postergando) equiparar seus salários ao de outras categorias, chega a ser quase bizarro tatear questôes menos sólidas como as que envolvem a singularidade, a alteridade, enfim, o investimento no trabalho psicológico em escolas.

Por mais que seja constatado o "mérito técnico-científico" de projetos voltados para a educação e saúde, não os desmerecendo, não se priorizam os aspectos humanos "da" e "na" escola. ${ }^{5}$ Assim, podemos destacar a urgência de implementação, em território nacional, de reivindicaçōes como as da Lei $n^{\circ}$ 10.881/2001 sancionada na Assembleia Legislativa de São Paulo, ou como o PL 443/2007, aprovado em 2013, mas cuja execução foi vetada pelo governador Geraldo Alckmin, neste ano. Esse e outros projetos de Lei semelhantes preveem o provimento público de profissionais de psicologia, serviço social e psicopedagogia para atuarem dentro ou fora dos estabelecimentos educacionais, em diversos níveis, desde o Ensino Infantil e Fundamental, até o Ensino Médio. Ora, uma política de formação e inserção contínua de profissionais na rede de ensino pública deve ser feita com o devido concurso público, embora essa realização esteja ainda muito distante. Com a presença de profissionais estáveis no quadro organizacional das escolas, isentos da subserviência imposta por práticas proselitistas típicas das contratações temporárias, seria possível garantir um patamar mínimo de liberdade política, necessária para se refletir sobre aquilo que se silencia no campo. Soma-se à desvalorização de educadores uma tendência atual a se inverterem os valores que deveriam ser construídos no bojo de uma escola democrática, e fundarem a assistência especializada unicamente em projetos vindos "de fora" da escola, tanto advindos da iniciativa privada quanto de pesquisas com financiamento público, o que não substitui a necessidade de psicólogos atuando regularmente em escolas.

Essa forma externa de oferta acaba pode gerar uma aderência quase direta de muitos professores e de muita famílias, a um discurso que se arvora a "resolver" problemas complexos com a chave de ouro de respostas simplistas, seja pela via da "medicalização", seja pela tentativa de "normalização", dos ditos "anormais", "desajustados", “delinquentes", “desviantes”, “bullies", "hiperativos”, e que, portanto, precisam se adaptar ou serão inevitavelmente "excluídos" do contexto educacional (CRPSP et al., 2010), sem dúvida, para serem reincluídos, ou melhor, reenquadrados em outros dispositivos disciplinares da saúde ou prisional. Assim, 
a tentativa de inclusão se transveste de "normalização" (FOUCAULT, 2002) e acaba por se tornar uma "inclusão-excludente", na medida em que se busca "endireitar" as diferenças, ao invés de reconhecer a alteridade, seus espaços de convivência e de inevitável atrito.

\section{A atual configuração das políticas de inserção de psicólogos}

Diante desse contexto de ausência de psicólogos nas instituições escolares, encontramos todo um movimento político de tentativa de implementação de práticas psicológicas regulares em escolas, através da exigência de concurso público. Há grande apoio dos Conselhos (Conselho Federal de Psicologia e Conselhos Regionais de Psicologia) em aprovar leis nesse sentido. Embora haja serviços especializados em Psicologia voltados para receber alunos com diversos tipos de dificuldades, em geral focam mais os aspectos psicopatológicos, logo não abrangem os conflitos cotidianos presentes nas escolas ${ }^{6}$.

Para atender as demandas mais abrangentes direcionadas aos psicólogos, podemos citar algumas iniciativas, embora ainda não tenham encontrado o devido êxito. Por exemplo, o Projeto e Lei no 441/2007, de autoria do deputado Marcos Martins, do PT, exige a inclusão de psicólogos e assistentes sociais na rede pública para atendimento de demandas advindas de escolas junto ao sistema de saúde. Seu argumento apresenta uma premissa contundente:

Nossa sociedade registra altos índices de desajuste social manifestos na indisciplina escolar e, de forma mais intensa, nos níveis de violência dentro e fora das escolas. As famílias, principalmente as mães, têm cada vez menos tempo para participar da educação de seus filhos, seja pela escassa convivência familiar, seja no acompanhamento da realização das tarefas escolares [...] (grifo da autora) ${ }^{7}$.

Ao mostrar a condição precária e de violência em que vivem e são educadas nossas crianças e jovens de menor renda, o deputado aponta também para a questão da indisciplina, sustentando uma necessidade de apoio externo, a ser oferecido pela área de saúde. Essa proposta, apesar de válida, não contribui especificamente para a inserção de psicólogos dentro das escolas. Afinal, a abertura a novas perspectivas dentro da escola, sobretudo de orientação psicanalítica, em vez de simplesmente "combater a violência e a indisciplina escolar", possibilita lidar com os afetos por outra via, da integração da agressividade em processos criativos e sublimatórios diretamente na escola. Com isso, tem-se a chance de 
evitar que muitos problemas surgidos, no escopo educacional sejam prontamente

empurrados para o gargalo do sistema de saúde. Outro exemplo é o distanciamento dos psicólogos em relação ao campo educacional lotados nas Coordenadorias Regionais de Educação, ao invés de atuarem mais diretamente nas escolas municipais do Rio de Janeiro. Essa forma de separação acaba por escalonar a atuação entre psicólogos, assistentes sociais e educadores, já que os primeiros vêm sempre de fora impor suas técnicas aos educadores. Contudo, há também projetos voltados para a inserção de psicólogos e assistentes sociais diretamente nas escolas públicas, mas as resistências a esse processo são evidentes, haja vista o recente veto dado pelo governador Geraldo Alckimin ao PL 442/07, de autoria da deputada Ana do Carmo (PT).

Além da iniciativa paulista, há uma Comissão do Senado que vem buscando a aprovação do Projeto de Lei PLC 060/2007, para a inserção de atendimento psicológico em escolas públicas. O projeto prevê a consolidação de:

[...] equipes multiprofissionais [capazes de] desenvolver açōes voltadas para a melhoria da qualidade do processo ensino-aprendizagem - o que deverá ser feito com a participação da comunidade escolar. Esses profissionais deverão também servir de mediadores nas relaçôes sociais e institucionais ${ }^{8}$.

É possível perceber uma influência do pensamento de Vigotski (1989) nessa proposta, pautada na "mediação" da relação dos profissionais com as famílias e com os estudantes, em vez de uma expectativa de "consertar" características subjetivas e emocionais abstratas, remediando diretamente os alunos. Na perspectiva psicanalítica, que, a nosso ver, não exclui a importância da mediação simbólica (ibid.), não se pode simplesmente "eliminar o conflito", mas sim, elaborá-lo com base na troca discursiva e na valorização do potencial transformador da palavra. Para além da identificação dos estudantes com seus educadores (FREUD, 1996), é necessário compreender as vicissitudes da transmissão do desejo de saber (QUINET, 2002), buscando refletir sobre a sutileza de aspectos conscientes e inconscientes presentes nas relaçôes educacionais. Há algumas iniciativas nesse sentido, com a oferta de "conversaçôes" com professores e jovens nas escolas".

A luta pela inserção de profissionais de saúde e humanas nas escolas, sobretudo assistentes sociais e psicólogos, é mais ampla do que criar um simples processo de contratações ou de projetos impositivos e/ou esporádicos. Depende, portanto, de uma verdadeira revolução nas micropolíticas vigentes, em que o total contingente de mentalidades atuantes na escola possa ser conscientizado do compromisso 
com a exigência de seus direitos, além da obrigação ética de promover a saúde psíquica e a educação de nossas crianças. Se essas condições não são priorizadas, enfatizando o cuidado com os sujeitos em suas características singulares, pouco se fará para minimizar a violência e aprimorar os rumos da educação.

\section{Referências}

ARREGUY, M. E. Da violência física à violência simbólica: expressões e inversōes na hierarquia professor-aluno. IN: SEMINÁRIO INTERNACIONAL "CONTRIBUTOS DA PSICOLOGIA EM CONTEXTOS EDUCATIVOS”, 1. Anais... Braga: Universidade do Minho, 2005, p. 929-940.

. Um lugar para a escuta psicanalítica no campo das aprendizagens. Aleph. Niterói,

v. 5, p. $1-12,2011$.

ARREGUY, M.E.; TORRES, M.M.; CAMPOREZ, G. Violência simbólica e fracasso escolar: reflexōes psicanalíticas na educação Aleph. Niterói, v. VI, p. 53-70, 2012.

ARREGUY, M.E.; GONTRAN, W. Face à la violence et ses effets dans le champ des apprentissages, quel espace pour une écoute? Recherches en Psychanalyse, v. 2012/2, p. 175a-185a, 2012.

AULAGNIER, P. Les destins du plaisir. Paris: PUF, 1979.

BATISTA, V.M. Memória e medo na cidade do Rio de Janeiro. O olho da história, Salvador, n. 14, jun 2010. Disponível em:http://oolhodahistoria.org/n14/artigos/vera.pdf Acesso em: 03 abr 2012.

BOURDIEU, P. Sobre el poder simbolico. In: . Intelectuales, politica y poder. Buenos Aire: Eudeba, 1990. p. 65-73.

. Qu'est-ce que c'est la psychologie. Disponível na internet: http://cahiers.kingston. ac.uk/vol02/cpa2.1.canguilhem.html. 1956. Acesso em: 03 abr 2013.

CARVALHO, Salo de. Observações sobre as (dis)funçôes do controle penal na sociedade contermporânea. In: MENEGAT, M.; NERI, R. (Org.). Criminologia e Subjetividade. Rio de Janeiro: Lumen Juris, 2005, p. 31-40.

CONSELHO REGIONAL DE PSICOLOGIA. SÃO PAULO. Medicalização de crianças e adolescentes. São Paulo: Casa do Psicólogo, 2010.

COSTA, M. V. et al. Caminhos investigativos: novos olhares na pesquisa em Educação. Rio de Janeiro: DP\&A, 2002.

DEBORD, G. A sociedade do espetáculo. EbooksBrasil, 1997. Disponível em: http://www. ebooksbrasil.com/eLibris/socespetaculo.html Acesso em: 12 jun 2013. 
DUFOUR, Dany-Robert. A cidade perversa: liberalismo e pornografia. Rio de Janeiro:

Civilização Brasileira, 2009.

ESTEVE, J.M.Z. O mal-estar docente: a sala de aula e a saúde dos professores. Bauru: Edusc, 1999.

FORRESTER, V. O horror econômico. São Paulo: UNESP, 1997.

FOUCAULT, M. A Verdade e as formas Jurídicas. Rio de Janeiro: PUC-RJ, 1974. . Microfísica do Poder. Rio Janeiro: Graal, 2000.

. Ditos e Escritos I. Problematização do sujeito : Psiquiatria, psicologia e psicanálise.

Rio de Janeiro: Forense Universitária, 2002.

FREUD, S. As resistências à Psicanálise. In: - Edição Standard Brasileira das Obras Psicológicas Completas de Sigmund Freud, v. XIX. Rio de Janeiro: Imago, 1996.

JAMES, W. A psicologia e a arte de ensinar. Cognitio-Estudos. Revista Eletrônica de Filosofia, v. 7, n. 2, 2010. Disponível em: http://revistas.pucsp.br/index.php/cognitio/article/view/3479 KUPFER, M.C. Freud e a Educação. São Paulo: Scipione, 1983. Educação para o futuro. Psicanálise e Educação. SP: Escuta, 2000.

LAJONQUIÈRE, L. Figuras do infantil: a psicanálise na vida cotidiana com crianças. Petrópolis: Vozes, 2010.

MIJOLLA-MELLOR, S. O engajamento político dos intelectuais. Reverso, Belo Horizonte, v. 64, p. 73-84, 2012.

NUBILE, M. A infância sob controle e a educação. Cien-Digital 15, nov. 2013. Disponível em: http://www.institutopsicanalise-mg.com.br/ciendigital/n15/cinecien.html

TSUJI, E.; MOYSES, M.A.; BATISTA, C. Diferentes olhares em relação a uma criança com múltiplos diagnósticos: estabilidade ou possibilidade de mudança? Psicologia: Reflexão e Critica, v. 24, n. 4., p. 720-729, 2011.

PATTO, M.H.S. A construção do fracasso escolar. São Paulo: T. A. Queiroz, 1990.

QUINET, A. Saber, olhar. In: Um olhar a mais: ver e ser visto em psicanálise. Rio de Janeiro: Jorge Zahar, 2002. p. 253-270.

ROCHA, M.; AGUIAR, K. Entreatos: percursos e construções da psicologia na rede pública de ensino. Estudos e Pesquisas em Psicologia. Rio de Janeiro, ano 10, n. 1, p. 68-84, 2010. Disponível em www.revispsi.uerj.br/v10n1/artigos/pdf/v10n1a06.pdf Acesso em: 01 $\operatorname{dez} 2013$.

RODRIGUES, H.B.C. et al. (Orgs.). Grupos e instituiçôes em análise. Rio de Janeiro: Rosa dos Tempos, 1995.

RORTY, R. Phylosophy and the mirror of nature. Princeton: Princeton University Press, 1979. 
ROUDINESCO, E. Por que a psicanálise? Rio de Janeiro: Zahar, 1999.

SANTOS, B. de $S$. Um discurso sobre as ciências na transição para uma ciência pósmoderna. Estudos Avançados, v. 2, n. 2, p. 46-71, dez. 1988. Disponível em: http://www. scielo.br/scielo.php? script $=$ sci_arttext\&pid $=$ S010340141988000200007\&lng=en \&tlng= pt Acesso em: $12 \mathrm{dez} 2013$.

SIBILIA, P. Redes ou paredes: a escola em tempos de dispersão. Rio de Janeiro: Contraponto, 2012.

SUWANN, L. Premiação teve pouco efeito em sala de aula. O Globo, 23 abr 2011.

VASCONCELOS, R.N. Violência escolar: uma das manifestações contemporâneas do fracasso escolar. Tese (Doutorado em Educação) - Faculdade de Educação, Universidade Federal de Minas Gerais, Belo Horizonte, 2010.

VIGOTSKI, L.S. A formação social da mente. São Paulo: Martins Fontes, 1989.

ŽIŽEK, S. Violence. New York: Picador, 2008.

Primeiro como tragédia, depois como farsa. São Paulo: Boitempo, 2011.

\section{Notas}

${ }^{1}$ Quando os dados quantitativos de nossa pesquisa (2010 a 2012) foram revelados em abril de 2012, a pedido da jornalista da Universidade Federal Fluminense, Maria Lea Aguiar (ou seja, de que 68\% dos educadores entrevistados afirmam haver algum tipo de violência na escola e $85 \%$ das escolas não têm psicólogos), fomos "atacados" por uma onda de jornalistas, que poderíamos ironizar como um nonsense à moda do filme de Wood Allen (2012), Para Roma com amor. Enquanto coordenadora da pesquisa, fui entrevistada ao vivo pela rádio $\mathrm{CBN}$, pela Band News, concedi entrevistas ao Jornal do SBT, ao RJTV, ao Repórter Brasil e ao Jornal da Band. A pesquisa saiu em reportagem de capa do jornal O Fluminense, além de ter sido noticiada pelos jornais Metro, O Globo e revista Carta Capital. Na internet, houve uma propagação enorme dos dados divulgados, sobretudo pela entrevista concedida a Flávia Vilella, da Agência Brasileira de Notícias. Interessante notar que algumas reportagens eram tendenciosas, "puxando" a notícia para o lado moralista do bullying, ou então fazendo uso político da informação para corroborar a introdução de policiais nas escolas estaduais do Rio de Janeiro. Ver referências das reportagens no currículo Lattes da autora.

${ }^{2}$ Designações de transtornos de comportamento e aprendizagem, respectivamente: transtorno de déficit de atenção e hiperatividade, transtorno de ansiedade generalizada, transtorno obsessivo compulsivo, transtorno opositivo desafiador, conforme DSM-IV e DSM-V.

${ }^{3}$ O governador Sérgio Cabral, no ano de 2012, anunciou programa de introdução de policiais militares nas escolas estaduais do Rio de Janeiro como forma de erradicar a violência. Ver: http://www. rj.gov.br/web/seseg/exibeconteudo?article-id=907265 (acessado em 07/12/2013). Tal política pública, anunciada em 05/05/2012, justificou o feito com base no alto índice de violência nas escolas.

${ }^{4}$ Ver, por exemplo, os seguintes projetos de lei tramitando no Congresso Nacional Brasileiro, que solicitam a contratação de psicólogos e assistentes sociais para trabalhar nas escolas e/ou no sistema de saúde para atender a demandas escolares: PL 3.688/2000; PL 837/2003, PL 1.497/2003, PL 1.674/2003, PL 2.513/2003, PL 2.855/2004, PL 3.154/2004; PL 3.613/2004; PL 1.031/2003; PL 4.738/2004; PL 442/2007 SP. 
${ }^{5}$ Diferencio aqui como recursos humanos "da" escola, isto é, dos profissionais concursados e estáveis e/ou com chance de adquirir estabilidade, dos recursos humanos "na" escola, que se caracterizam por serem temporários, cíclicos, instáveis e sujeitos à distorção por interesses privados e/ou políticos. ${ }^{6}$ A título de exemplo, algumas escolas terapêuticas, como: Parc de Saint-Cloud - Ville d'Avray; École Experimentale de Bonneiul-Sur-Marne; La Vie au Grand Air - Fondation - Maintes La Jolie; Escola Terapêutica Lugar de Vida - São Paulo; Casa da Àrvore; etc.

${ }^{7}$ Ver www.pol.org.br ou www.crpsp.org.br, ou também http://www.crpsp.org.br/portal/midia/fi

${ }^{8}$ Ver http://www.radiowanteds.com.br/teste/?p=428. Os projetos de lei aqui mencionados são acessíveis através da página do Conselho Federal de Psicologia: www.pol.org.br

${ }_{9}^{9}$ Por exemplo, Vasconcelos (2010) e Nubile (2013). Ver também http://www.institutopsicanalisemg.com.br/ciendigital/n15/cinecien.html 


\section{Abstract}

\section{Violence and absence of psychologists in schools}

We seek to reflect on the priority of psychological practice in the school regional context, analyzing its nuances and identifying the deadlock that hinder psychological work in regular schools. In order to answer the questions raised during ten years lecturing theoretically on this subject, we investigate: Which would be the practical dimension of the course "Psychology of Education"? To this end, the following activities were carried out in the field: direct observations and semistructured interviews with psychologists, teachers and other professionals working in public and private schools in the Brazilian cities of Niteroi, Rio de Janeiro, São Gonçalo and Itaboraí. In a theoretical and descriptive essay, we showed the main problems reported: the huge shortage of psychologists working in schools and some aspects of violence in this context. We also note that the work of psychologists in schools presents a paradox: the action in favor of the emergence of the word versus the resistance on the part of the institution, school, "ordering" silence, adaptation and correction of undesirable conduct, thus undermining uniqueness.

> Key words: psychoanalysis and education; violence in schools; symbolic violence, public policies. 